ZOOTECNIA

\title{
ALTURA INICIAL E PERÍODO DE DIFERIMENTO EM PASTOS DE CAPIM-BRAQUIÁRIA
}

\section{INITIAL HEIGHT AND DEFERMENT PERIOD ON SIGNALGRASS PASTURES}

\author{
Francisco de Souza Gouveia ${ }^{1}$ \\ Dilermando Miranda da Fonseca ${ }^{1}$ \\ Manoel Eduardo Rozalino Santos ${ }^{2}$ \\ Virgilio Mesquita Gomes ${ }^{3}$ \\ Angélica Nunes de Carvalho ${ }^{*}$
}

1Universidade Federal de Viçosa, Viçosa, MG, Brasil.

2Universidade Federal de Uberlândia, Uberlândia, MG, Brasil.

3Universidade Estadual de Montes Claros, Montes Claros, MG, Brasil.

*Autora para correspondência - angelicanunescoro@hotmail.com

\section{Resumo}

Avaliaram-se as alturas iniciais $(10,20$ e $30 \mathrm{~cm})$ e os períodos de diferimento (171, 141 e 109 dias em 2010; e 131, 100 e 71 dias em 2011) da Urochloa decumbens cv. Basilisk (capim-braquiária). Os fatores foram arranjados em parcelas subdivididas e em delineamento de blocos completos casualizados, com três repetições. Os pastos diferidos por curto período apresentaram menores massas de forragem (5.977 e $6.904 \mathrm{~kg} / \mathrm{ha}$ de MS em 2010 e 2011, respectivamente). Em 2010, os pastos diferidos por curto período apresentaram menor massa de colmo vivo ( $942 \mathrm{~kg} / \mathrm{ha}$ de MS), de lâmina foliar morta (785 kg/ha de MS) e de colmo morto (1.282 kg/ha de MS), maiores números de perfilhos vegetativos ( 797 perfilhos $/ \mathrm{m}^{2}$ ) e menores de reprodutivos (2 perfilhos $/ \mathrm{m}^{2}$ ), menor índice de tombamento $(1,4)$ e superior massa de lâmina foliar viva $(655 \mathrm{~kg} / \mathrm{ha}$ de MS). Os pastos mais altos apresentaram menor número de perfilhos vegetativos (495 e 431 perfilhos/m² em 2010 e 2011, respectivamente), maiores massas de forragem (5.285 e $5.942 \mathrm{~kg} / \mathrm{ha}$ de MS em 2010 e 2011, respectivamente), de lâmina foliar morta (968 kg/ha de MS em 2010) e de colmo morto (1.902 kg/ha de MS em 2010). Com base nos resultados obtidos nos dois anos, para utilização em julho, o capimbraquiária pode ser diferido por 71 a 109 dias, com altura inicial de 20 a $30 \mathrm{~cm}$. A altura inicial de 10 cm é recomendada quando se adota período de diferimento acima de 130 dias.

Palavras-chave: estrutura do pasto; massa de forragem; perfilho; Urochloa decumbens.

\begin{abstract}
This study aimed to evaluate the initial heights $(10,20$, and $30 \mathrm{~cm})$ and deferment periods $(171,141$, and 109 days in 2010; and 131, 100, and 71 days in 2011) of Urochloa decumbens cv. Basilisk (signal grass). The factors were arranged in split plot, in a randomized complete block design with three
\end{abstract}


replications. Pastures deferred for a short period had lower masses of forage $(5,977$ and $6,904 \mathrm{~kg} / \mathrm{ha}$ of DM in 2010 and 2011, respectively). In 2010, pastures deferred for a short period had lower mass of live stem $(942 \mathrm{~kg} / \mathrm{ha}$ of DM), dead leaf blade $(785 \mathrm{~kg} / \mathrm{ha}$ of DM), and dead stem $(1282 \mathrm{~kg} / \mathrm{ha}$ of DM), higher number of vegetative tillers (797 tillers $\left./ \mathrm{m}^{2}\right)$, fewer reproductive tillers (2 tillers $\left./ \mathrm{m}^{2}\right)$, less falling index (1.4), higher mass of live leaf blade (655 kg/ha of DM). The higher pastures had fewer vegetative tillers (495 and 431 tillers $/ \mathrm{m}^{2}$ in 2010 and 2011, respectively), larger masses of forage (5,285 and 5,942 kg/ha of DM in 2010 and 2011, respectively), dead leaf blade (968 kg kg/ha of DM in 2010) and dead stem (1,902 kg/ha of DM in 2010). Based on the results obtained in the two years, for use in July, the signal grass can be deferred for 71-109 days with an initial height of 20 to $30 \mathrm{~cm}$. The initial height of $10 \mathrm{~cm}$ is recommended when a deferral period above 130 days is adopted.

Keywords: Brachiaria decumbens; forage mass; sward height; tiller.

Recebido em: 17 outubro de 2016

Aceito em: 30 junho de 2017

\section{Introdução}

O diferimento de pastagens consiste em excluir do pastejo determinada área no final da estação de crescimento da planta forrageira, possibilitando, com isso, que se acumule forragem para ser utilizada durante a entressafra ${ }^{(1-3)}$. De maneira geral, pastos diferidos por maior período produzem mais massa de forragem, porém com superiores percentuais de colmo, forragem morta e perfilhos reprodutivos, o que ocasiona menor valor nutritivo ${ }^{(4)}$ e redução da eficiência de pastejo. Um período de diferimento curto melhora o valor nutritivo e a eficiência de pastejo, devido ao maior percentual de folhas verdes, menor tombamento de plantas e maior número de perfilhos vegetativos no pasto diferido; entretanto, produz menos forragem ${ }^{(4)}$, que pode ser insuficiente para alimentação do rebanho na entressafra.

Outro fator que influencia as características do pasto diferido é a sua altura no início do diferimento. Com pasto baixo, há maior penetração de luz até a superfície do solo, estimulando o aparecimento de novos perfilhos vegetativos e de melhor valor nutritivo ${ }^{(5-7)}$. Por outro lado, pasto alto favorece uma maior massa de forragem no inverno, porém pode implicar menor eficiência de pastejo devido à maior possibilidade de ocorrer tombamento das plantas de maior tamanho.

O conhecimento dos efeitos do período de diferimento e da altura inicial da planta forrageira sobre a estrutura de pastos diferidos é premissa para melhoria da produção animal em pastagens diferidas, na medida em que o comportamento ingestivo e o desempenho animal são determinados pela forma como o pasto é disponibilizado para o animal em pastejo ${ }^{(8,9)}$.

Assim, este trabalho foi desenvolvido com o objetivo de determinar a(s) altura(s) inicial(is) e o(s) período(s) de diferimento da $U$. decumbens cv. Basilisk que resultem em pastos diferidos com estrutura apropriada para o animal durante o inverno. 


\section{Material e Métodos}

Esta pesquisa foi realizada no período de janeiro a julho dos anos 2010 e 2011, em pastagem com Urochloa decumbens cv. Basilisk Stapf., pertencente ao Setor de Forragicultura do Departamento de Zootecnia da Universidade Federal de Viçosa (UFV), localizado em Viçosa, Estado de Minas Gerais, a $20^{\circ} 45^{\prime} \mathrm{S} ; 42^{\circ} 51^{\prime \prime} \mathrm{W}$ e $651 \mathrm{~m}$ de altitude. As áreas experimentais utilizadas em 2010 e 2011 foram diferentes.

O clima de Viçosa, pelo sistema de Köppen ${ }^{(10)}$, é do tipo Cwa, com estações seca (maio a outubro) e chuvosa (novembro a abril) bem definidas. A precipitação média anual é de $1.340 \mathrm{~mm}$, com umidade relativa média do ar de $80 \%$, temperatura média anual de $19{ }^{\circ} \mathrm{C}$ e altitude de $651 \mathrm{~m}$. Os dados climáticos registrados durante o experimento foram monitorados (Tabela 1).

Tabela 1. Médias mensais de temperatura diária média, máxima e mínima e precipitação mensal total de Janeiro a Julho de 2010 e de 2011

\begin{tabular}{ccccc}
\hline Mês & $\begin{array}{c}\text { Temperatura } \\
\text { Média }\left({ }^{\circ} \mathbf{C}\right)\end{array}$ & $\begin{array}{c}\text { Temperatura } \\
\text { máxima }\left({ }^{\circ} \mathbf{C}\right)\end{array}$ & $\begin{array}{c}\text { Temperatura } \\
\text { mínima }\left({ }^{\circ} \mathbf{C}\right)\end{array}$ & $\begin{array}{c}\text { Precipitação } \\
(\mathbf{m m})\end{array}$ \\
\hline Janeiro & 23,4 & 31,5 & 18,3 & 126,2 \\
Fevereiro & 23,9 & 31,8 & 21,5 & 38,9 \\
Março & 22,9 & 29,2 & 19,1 & 184,8 \\
Abril & 20,4 & 27,1 & 16,3 & 28,1 \\
Maio & 18,4 & 24,9 & 14,3 & 35,4 \\
Junho & 15,3 & 23,5 & 9,9 & 0,9 \\
Julho & 17,3 & 25,0 & 12,4 & 0,0 \\
& & & 2011 & \\
Janeiro & 21,5 & 29,2 & 19,8 & 141,0 \\
Fevereiro & 22,7 & 30,9 & 18,9 & 141,0 \\
Março & 22,1 & 27,5 & 19,1 & 284,4 \\
Abril & 20,8 & 26,9 & 17,3 & 56,6 \\
Maio & 17,6 & 24,7 & 13,7 & 2,6 \\
Junho & 15,9 & 23,1 & 11,5 & 23,0 \\
Julho & 15,6 & 24,1 & 9,9 & 0,0 \\
\hline
\end{tabular}

O solo das áreas experimentais foi classificado como Latossolo Vermelho-Amarelo, de textura argilosa e com relevo medianamente ondulado. As características químicas, na camada de 0 a $20 \mathrm{~cm}$ de profundidade, são apresentadas na Tabela 2, sendo Área 1 referente ao ano 2010 e Área 2, ao ano 2011.

Não foram realizadas correções de $\mathrm{pH}$, fósforo e potássio no solo, em razão da boa condição do pasto e também da época tardia em que foi estabelecido o experimento, já que a calagem e adubação de manutenção fosfatada e potássica são recomendadas no início da estação chuvosa ${ }^{(11)}$. No entanto, foi realizada adubação nitrogenada com aplicação de $70 \mathrm{~kg} / \mathrm{ha}$ de $\mathrm{N}$ na forma de ureia, em única aplicação 
no início do diferimento.

Tabela 2. Características químicas de amostras de solo da camada de $0-20 \mathrm{~cm}$ de profundidade, nas áreas experimentais em 2010 e 2011

\begin{tabular}{|c|c|c|c|c|c|c|c|c|c|}
\hline \multirow{2}{*}{ Identificação } & \multirow{2}{*}{$\begin{array}{c}\mathrm{pH} \\
\mathrm{H}_{2} \mathrm{O}\end{array}$} & \multirow{2}{*}{\multicolumn{2}{|c|}{$\begin{array}{cc}\mathbf{P} & \mathbf{K} \\
--\mathbf{m g} \cdot \mathbf{d m}^{-3}--\end{array}$}} & \multirow{2}{*}{$\mathrm{Ca}^{2+}$} & \multirow[t]{2}{*}{$\mathrm{Mg}^{2+}$} & \multirow[t]{2}{*}{$\mathbf{A l}^{3+}$} & \multirow{2}{*}{$\begin{array}{l}\mathbf{H}^{+}+\mathbf{A l}^{3+} \\
\mathbf{d m}^{-3}\end{array}$} & \multirow{2}{*}{$\begin{array}{r}\mathbf{T} \\
--\end{array}$} & \multirow{2}{*}{$\begin{array}{c}\mathbf{V}_{\%} \mathbf{m} \\
\%\end{array}$} \\
\hline & & & & & & & & & \\
\hline Área 1 - 2010 & 5,5 & 2,9 & 42 & 0,9 & 0,3 & 0,3 & 3,47 & 4,78 & $27 \quad 19$ \\
\hline Área 2 - 2011 & 5,6 & 2,8 & 62 & 1,1 & 0,5 & 0,1 & 3,71 & 5,52 & 338,7 \\
\hline
\end{tabular}

$\mathrm{P}$ e K foram analisados com $\mathrm{HCl} 0,05 \mathrm{~mol} / \mathrm{L}+\mathrm{H}_{2} \mathrm{SO}_{4} 0,0125 \mathrm{~mol} / \mathrm{L} ; \mathrm{Ca}^{2+}, \mathrm{Mg}^{2+} \mathrm{e} \mathrm{Al}{ }^{3+}$ foram analisados com solução tampão $\mathrm{SMP}$ a pH 7,5; T: CTC a pH 7,0; V: saturação de bases; m: saturação de alumínio.

Em ambos os anos (2010 e 2011) foram avaliadas combinações de três períodos de diferimento com três alturas iniciais do pasto. Os períodos foram resultantes de três épocas para o início do diferimento, quais sejam: 27/01/2010, 26/02/2010 e 30/03/2010 no primeiro ano; e 28/02/2011, 31/03/2011 e 29/04/2011 no segundo ano experimental. Em ambos os anos foram avaliadas as mesmas alturas dos pastos no início do diferimento $(10,20$ e $30 \mathrm{~cm})$. Contudo, os períodos de diferimento foram diferentes para cada ano, sendo de 171, 141 e 109 dias em 2010 e de 131, 100 e 71 dias em 2011.

$\mathrm{O}$ experimento foi conduzido em esquema de parcelas subdivididas, sendo utilizado o delineamento em blocos completos casualizados com três repetições, em 2010 e 2011 . Os períodos de diferimento foram correspondentes ao fator primário (parcela) e as alturas iniciais dos pastos, ao fator secundário (subparcela). A área da parcela foi de $12 \mathrm{~m}^{2}(2 \times 6 \mathrm{~m})$ e a da subparcela, de $4 \mathrm{~m}^{2}(2 \times 2 \mathrm{~m})$. A distância entre cada bloco foi de $1 \mathrm{~m}$.

$\mathrm{Na}$ data inicial do diferimento, as parcelas foram rebaixadas com roçadeira costal para as alturas almejadas. Em seguida, removeu-se o excesso de forragem das parcelas e foi aplicado $70 \mathrm{~kg} / \mathrm{ha} \mathrm{de} \mathrm{N}$, na forma de ureia. Em 2010, os pastos foram diferidos até 17 de julho e em 2011, até sete de julho, quando foram realizadas as avaliações.

A densidade populacional de perfilhos foi mensurada com a colheita de três amostras por subparcela em 2010 e duas em 2011. O menor número de colheitas em 2011 ocorreu, pois constatou-se pouca variabilidade dos dados de densidade populacional de perfilhos no ano anterior. Utilizou-se moldura de vergalhão com $25 \mathrm{~cm}$ de lado. Os perfilhos no interior da moldura foram cortados rente ao solo e levados ao laboratório, onde foram quantificados em vegetativos e reprodutivos. Os perfilhos vivos sem inflorescência visível foram denominados de vegetativos e os perfilhos vivos com inflorescência visível, de reprodutivos.

A altura do pasto foi determinada considerando-se a distância entre a parte mais alta da planta no pasto e o nível da superfície do solo. A altura da planta estendida foi determinada para possibilitar o cálculo do índice de tombamento, estendendo-se os perfilhos da gramínea no sentido vertical e anotando-se a maior distância do nível do solo ao ápice dos perfilhos. O índice de tombamento do pasto foi estimado pelo quociente entre a altura da planta estendida e a altura do pasto $^{(1)}$.

A massa de forragem e de seus componentes morfológicos foi avaliada nos dois anos experimentais e as massas dos componentes morfológicos da forragem somente em 2010. Foram colhidas três amostras na parte central de cada subparcela, utilizando-se quadrado de vergalhão com $50 \mathrm{~cm}$ de lado x 0,5 . O corte dos perfilhos foi ao nível da superfície do solo, com tesoura de poda. Em seguida, as 
amostras foram acondicionadas em sacos plásticos e, no laboratório, pesadas e subdivididas em duas subamostras. Uma delas foi pesada, acondicionada em sacos de papel e colocada em estufa com circulação forçada de ar a $65^{\circ} \mathrm{C}$, durante $72 \mathrm{~h}$, quando foi retirada e novamente pesada. A segunda subamostra foi separada em lâmina foliar viva, colmo vivo, lâmina foliar morta e colmo morto. Após a separação, os componentes foram secos em estufa com circulação forçada de ar a $65{ }^{\circ} \mathrm{C}$, durante 72 $\mathrm{h}$, e pesados.

Para a análise estatística, todo o conjunto de dados foi testado de forma a assegurar que os princípios básicos da análise de variância fossem atendidos. Com isso, foi necessário que o índice de tombamento tivesse seus dados transformados para logaritmo de base 10. Para cada característica, realizou-se a análise de variância com o objetivo de desdobrar a soma de quadrados de tratamentos nas partes relativas a cada fator (altura e período) e na parte relativa à interação entre os fatores. Quando a interação entre os fatores não foi significativa, realizou-se a comparação entre as médias marginais dos níveis dos fatores, de acordo com a sua significância. No caso de interação significativa entre os fatores, procedeu-se à comparação dos níveis de um fator em separado para cada nível do outro fator. As médias foram comparadas pelo teste de Student-Newman-Keuls, adotando-se $\alpha=0,05$ nas análises estatísticas.

\section{Resultados e Discussão}

A densidade populacional de perfilhos vegetativos diminuiu com o incremento do período de diferimento nos dois anos e aumentou com a redução da altura inicial do pasto em 2011 (Tabela 3). Com maior período de diferimento, grande parte dos perfilhos vegetativos se desenvolveu em reprodutivos $^{(12)}$ (Tabela 4). Em 2011, a menor altura inicial proporcionou maior número $(p<0,05)$ de perfilhos vegetativos, pois o rebaixamento aumenta a incidência de luz na base das plantas, o que estimula o surgimento de novos perfilhos ${ }^{(13)}$. Nos pastos diferidos com maiores alturas $(20 \mathrm{e} 30 \mathrm{~cm})$ pode ter ocorrido maior sombreamento na base das plantas, o que inibiu o aparecimento de $\operatorname{perfilhos}^{(14)}$.

Em 2011, o pasto diferido por curto período (Período 3) apresentou menor número de perfilhos vegetativos que o sob médio período de diferimento (Período 2) (Tabela 3). Esse resultado foi contrário ao ocorrido no ano 2010. É possível que a reduzida precipitação pluvial durante os meses em que o capim-braquiária permaneceu diferido (2,6 mm em maio e 23,0 mm em junho - Tabela 1) sob curto período em 2011 (Tabela 1) tenha comprometido o desenvolvimento de novos perfilhos e/ou causado a morte dos perfilhos.

O número de perfilhos reprodutivos aumentou $(\mathrm{p}<0,05)$ com o período de diferimento em ambos os anos (Tabela 3). Com maior período de diferimento, grande parte dos perfilhos vegetativos se desenvolve em perfilhos reprodutivos ${ }^{(12)}$. Além disso, a concentração do florescimento do capimbraquiária em Viçosa, MG, ocorre entre fevereiro e maio ${ }^{(15)}$. Dessa forma, os pastos diferidos mais cedo no ano (janeiro e fevereiro) e, consequentemente, com maior período de diferimento ficaram por maior tempo em crescimento livre, que coincidiu com o período de concentração do florescimento. Entretanto, os pastos diferidos mais tardiamente (março e abril), com menor período 
de diferimento, foram rebaixados na época de florescimento mais intenso. Com isso, possivelmente, muitos perfilhos que iniciaram a fase reprodutiva tiveram seu meristema apical eliminado, o que diminuiu a ocorrência de perfilhos reprodutivos. Ademais, o menor período de diferimento destes pastos também pode ter contribuído para a redução da densidade populacional de perfilhos reprodutivos $^{(1)}$.

Tabela 3. Número de perfilhos vegetativos $/ \mathrm{m}^{2}$ do capim-braquiária diferido com alturas e períodos variáveis nos dois anos experimentais

\begin{tabular}{ccccc}
\hline \multirow{2}{*}{ Altura (cm) } & \multicolumn{3}{c}{ Período de diferimento* $^{*}$} & \multirow{2}{*}{ Média } \\
\cline { 2 - 4 } & Período 1 & Período 2 & Período 3 & \\
\hline 10 & $366 \mathrm{c}$ & Ano 2010 & & 552 \\
20 & $252 \mathrm{c}$ & $544 \mathrm{~b}$ & $745 \mathrm{a}$ & 519 \\
30 & $224 \mathrm{~b}$ & $458 \mathrm{~b}$ & $848 \mathrm{a}$ & 495 \\
\hline Média & 281 & $348 \mathrm{~b}$ & $912 \mathrm{a}$ & \\
\hline & & 450 & 797 & $708 \mathrm{~A}$ \\
20 & 672 & Ano 2011 & & $535 \mathrm{~B}$ \\
30 & 349 & 857 & 579 & $431 \mathrm{~B}$ \\
\hline Média & 336 & 787 & 469 & \\
\hline
\end{tabular}

* Períodos de diferimentos 1, 2 e 3 correspondem a 171, 141 e 109 dias em 2010 e 131, 100 e 71 dias em 2011. Em cada ano, médias seguidas por diferentes letras minúsculas nas linhas e maiúsculas nas colunas diferiram pelo teste de Student-Newman-Keuls ( $\mathrm{p}<0,05)$.

Tabela 4. Número de perfilhos reprodutivos $/ \mathrm{m}^{2}$ do capim-braquiária diferido com alturas e períodos variáveis nos dois anos experimentais

\begin{tabular}{ccccc}
\hline \multirow{2}{*}{ Altura (cm) } & \multicolumn{3}{c}{ Período de diferimento* $^{*}$} & \multirow{2}{*}{ Média } \\
\cline { 2 - 4 } & Período l & Período 2 & Período 3 & \\
\hline & & Ano 2010 & & 193 \\
20 & 423 & 155 & 0 & 207 \\
30 & 357 & 265 & 0 & 158 \\
\hline Média & 272 & 199 & 5 & \\
\hline & $351 \mathrm{a}$ & $206 \mathrm{~b}$ & $2 \mathrm{c}$ & 81 \\
10 & 227 & Ano 2011 & & 90 \\
20 & 227 & 11 & 5 & 66 \\
\hline 30 & 141 & 19 & 24 & \\
\hline Média & $198 \mathrm{a}$ & 51 & 5 & $12 \mathrm{~b}$ \\
\hline
\end{tabular}

* Períodos de diferimentos 1, 2 e 3 correspondem a 171, 141 e 109 dias no ano 2010 e 131,100 e 71 dias no ano 2011. Em cada ano, médias seguidas por diferentes letras minúsculas nas linhas diferiram pelo teste de StudentNewman-Keuls $(\mathrm{p}<0,05)$.

A altura do pasto não influenciou ( $\mathrm{p}>0,05)$, nos dois anos experimentais, o número de perfilhos 
reprodutivos (Tabela 4). O período de diferimento mais longo pode ter anulado o efeito da altura inicial do pasto, já que, com períodos mais longos (pastos diferidos em janeiro e fevereiro), as condições climáticas foram mais favoráveis ao desenvolvimento das plantas (Tabela 1). Contudo, com períodos de diferimento curtos, era esperado que os pastos diferidos com maiores alturas (20 e $30 \mathrm{~cm}$ ) apresentassem maior número de perfilhos reprodutivos, devido à possibilidade da rebrotação ocorrer a partir de perfilhos mais velhos, que não tiveram seu meristema apical eliminado durante o corte no início do período de diferimento.

A altura do pasto diferido aumentou $(\mathrm{p}<0,05)$ com o período de diferimento (Tabela 5), nos dois anos experimentais. Um período de diferimento maior proporciona às plantas maior tempo para crescimento. Além disso, plantas diferidas em janeiro e fevereiro receberam maior quantidade de chuvas, bem como estavam em condições de maior temperatura média ao longo do período em que permaneceram diferidas, em comparação com aquelas diferidas em março ou abril (Tabela 1).

Tabela 5. Altura do pasto $(\mathrm{cm})$ do capim-braquiária diferido com alturas e períodos variáveis nos dois anos experimentais

\begin{tabular}{|c|c|c|c|c|}
\hline \multirow{2}{*}{ Altura (cm) } & \multicolumn{3}{|c|}{ Período de diferimento* } & \multirow{2}{*}{ Média } \\
\hline & Período 1 & Período 2 & Período 3 & \\
\hline \multicolumn{5}{|c|}{ Ano 2010} \\
\hline 10 & 36 & 44 & 23 & 34 \\
\hline 20 & 35 & 38 & 31 & 35 \\
\hline 30 & 37 & 40 & 32 & 36 \\
\hline Média & $36 a$ & $41 \mathrm{a}$ & $29 \mathrm{~b}$ & \\
\hline \multicolumn{5}{|c|}{ Ano 2011} \\
\hline 10 & 46 & 20 & 14 & 27B \\
\hline 20 & 41 & 30 & 21 & $31 \mathrm{~B}$ \\
\hline 30 & 50 & 40 & 33 & $41 \mathrm{~A}$ \\
\hline Média & $46 a$ & $30 \mathrm{~b}$ & $23 b$ & \\
\hline
\end{tabular}

A maior altura do pasto $(30 \mathrm{~cm})$ no início do diferimento resultou em sua maior $(\mathrm{p}<0,05)$ altura no fim deste período em 2011 (Tabela 5). Com maior altura inicial, possivelmente o pasto iniciou sua rebrotação com maior quantidade de perfilhos mais compridos que aqueles pastos rebaixados a uma altura menor, o que resultou em plantas mais altas ao término do diferimento. Já no ano 2010, a altura do pasto diferido não foi influenciada $(\mathrm{p}>0,05)$ pela altura inicial. A ausência de efeito da altura inicial em 2010 pode ser atribuída à menor precipitação pluvial registrada durante o diferimento, janeiro a julho, em comparação com o mesmo período de 2011 (Tabela 1).

Com relação ao índice de tombamento, este aumentou $(\mathrm{p}<0,05)$ com o período de diferimento, nos dois anos avaliados (Tabela 6). 
Tabela 6. Índice de tombamento do capim-braquiária diferido com alturas e períodos variáveis, em dois anos experimentais

\begin{tabular}{ccccc}
\hline \multirow{2}{*}{ Altura (cm) } & \multicolumn{3}{c}{ Período de diferimento } & \multirow{2}{*}{ Média } \\
\cline { 2 - 4 } & Período 1 & Período 2 & Período 3 & \\
\hline & \multicolumn{5}{c}{ Ano 2010 } & 1,5 & 1,7 \\
20 & 2,3 & 1,2 & 1,3 & 1,9 \\
30 & 2,4 & 2,0 & 1,3 & 1,8 \\
\hline Média & 2,2 & 2,0 & $1,4 \mathrm{c}$ & \\
\hline & $2,3 \mathrm{a}$ & $1,8 \mathrm{~b}$ & 1,3 & 1,5 \\
10 & 1,7 & Ano 2011 & 1,7 \\
20 & 2,2 & 1,4 & 1,5 & 1,6 \\
\hline 30 & 2,2 & 1,4 & 1,3 & \\
\hline Média & $2,0 \mathrm{a}$ & 1,3 & $1,4 \mathrm{~b}$ & \\
\hline
\end{tabular}

* Períodos de diferimentos 1,2 e 3 correspondem a 171, 141 e 109 dias no ano 2010 e a 131,100 e 71 dias no ano 2011. Em cada ano, médias seguidas por diferentes letras minúsculas nas linhas diferiram pelo teste de Student-Newman-Keuls ( $p<0,05)$.

Em 2010, o pasto diferido por 171 dias (Período 1) apresentou maior índice de tombamento (IT) que aquele diferido por 141 dias (Período 2), que, por sua vez, teve maior valor de IT em relação ao diferido por 109 dias (Período 3). Já no ano 2011, o pasto diferido por 131 dias apresentou maior IT que o diferido por 100 e 71 dias (Tabela 6). Santos et al. ${ }^{(1)}$ também relataram mesmo efeito do período de diferimento sobre o IT de $B$. decumbens. O colmo delgado e flexível do capim-braquiária explica a facilidade de tombamento dessa planta forrageira em idade mais avançada.

A altura inicial do pasto não teve efeito ( $p>0,05)$ sobre o IT dos pastos diferidos (Tabela 6). Em geral, tanto a altura do pasto quanto a altura da planta estendida aumentaram com a maior altura inicial do pasto diferido e, dessa forma, a relação entre essas variáveis não foi modificada.

Uma estratégia de manejo que poderia ser utilizada para reduzir o índice de tombamento em pastos diferidos e, consequentemente, também as perdas de forragem que estão associadas a essa condição seria a diminuição do período de diferimento, independentemente da altura inicial do pasto.

De modo geral, nos dois anos experimentais, a massa de forragem aumentou $(\mathrm{p}<0,05)$ com o período de diferimento (Tabela 7). Com o período de diferimento mais longo, as condições climáticas foram mais favoráveis ao desenvolvimento da planta (Tabela 1).

Em 2010, houve efeito da interação $(\mathrm{p}<0,05)$ entre período de diferimento e altura inicial do pasto sobre a massa de forragem (Tabela 7). Observou-se que os pastos diferidos por 171 dias (Período 1), independentemente da altura inicial, não apresentaram variação $(p>0,05)$ na massa de forragem. $O$ longo período em que o pasto permaneceu diferido provavelmente anulou o efeito da altura inicial. Já nos pastos diferidos por 109 dias (Período 2), a altura inicial de $10 \mathrm{~cm}$ proporcionou menor massa de forragem em relação ao pasto diferido com maior altura $(30 \mathrm{~cm})$. Essa menor massa de forragem no 
pasto diferido mais baixo pode ser justificada devido às menores altura e massa de forragem do pasto no início do diferimento.

Tabela 7. Massa de forragem (kg.ha-1 de MS) do capim-braquiária diferido com alturas e períodos variáveis em dois anos experimentais

\begin{tabular}{ccccc}
\hline \multirow{2}{*}{ Altura (cm) } & \multicolumn{3}{c}{ Período de diferimento* $^{*}$ Média } \\
\cline { 2 - 4 } & Período 1 & Periodo 2 & Período 3 & \\
\hline & & Ano 2010 & & \\
20 & $6.269 \mathrm{aA}$ & $4.331 \mathrm{bB}$ & $2.889 \mathrm{cB}$ & 4.497 \\
30 & $6.345 \mathrm{aA}$ & $5.314 \mathrm{aAB}$ & $3.985 \mathrm{bA}$ & 5.215 \\
\hline Média & $5.317 \mathrm{aA}$ & $6.423 \mathrm{aA}$ & $4.116 \mathrm{bA}$ & 5.285 \\
\hline & 5.977 & 5.356 & 3.664 & \\
10 & 6.749 & Ano 2011 & & 4.508 \\
20 & 6.487 & 3.841 & 2.933 & 5.447 \\
30 & 7.475 & 5.534 & 4.321 & 5.942 \\
\hline Média & $6.904 \mathrm{a}$ & 5.977 & 4.375 & \\
\hline
\end{tabular}

* Períodos de diferimentos 1,2 e 3 correspondem a 171,141 e 109 dias no ano 2010 e a 131,100 e 71 dias no ano 2011. Em cada ano, médias seguidas por diferentes letras minúsculas nas linhas e maiúsculas nas colunas diferiram pelo teste de Student-Newman-Keuls $(\mathrm{P}<0,05)$.

Mesmo com menor período de diferimento, porém com maior altura inicial do pasto, é possível obter resultados de massa de forragem semelhante aos encontrados quando os pastos mais baixos são diferidos por maior tempo. Essa interação entre período de diferimento e altura inicial do pasto pode flexibilizar o manejo do pasto na propriedade, aumentando as possibilidades de se obterem resultados semelhantes de massa de forragem com variações entre essas ações de manejo em pastos diferidos.

No segundo ano (2011), não houve interação entre as variáveis período de diferimento e altura inicial do pasto sobre a massa de forragem. O maior período de diferimento proporcionou maior $(\mathrm{p}<0,05)$ massa de forragem (Tabela 7). Entretanto, a altura inicial do pasto não influenciou ( $>0,05)$ a massa de forragem (Tabela 7).

A massa de forragem acumulada durante o período de diferimento é importante, pois influencia a taxa de lotação na pastagem durante o período de sua utilização. Com períodos de diferimento curtos e altura inicial de $10 \mathrm{~cm}$, a massa de forragem pode ser limitante, o que faz ser arriscado trabalhar com esse manejo. No entanto, além da avaliação da massa de forragem, o conhecimento sobre as massas de seus componentes morfológicos é igualmente relevante, porque permite caracterizar a estrutura do pasto e inferir sobre o seu valor nutritivo e potencial de consumo pelo animal.

Nesse sentido, observou-se que os pastos diferidos em janeiro (Período 1) e fevereiro (Período 2) apresentaram menor massa de lâmina foliar viva em relação ao pasto diferido em março (Período 3) (Tabela 8). Os pastos diferidos por período mais longo tiveram melhor disponibilidade de condições climáticas favoráveis ao crescimento (Tabela 1). Assim, esses pastos atingiram maiores alturas (Tabela 5), gerando provavelmente maior sombreamento no dossel, o que acarreta menor fotossíntese foliar em relação à respiração e, com efeito, a morte da folha sombreada, principalmente daquelas 
localizadas na parte basal do pasto ${ }^{(16)}$.

Tabela 8. Massa dos componentes da forragem do capim-braquiária diferido com alturas e períodos variáveis em 2010

\begin{tabular}{|c|c|c|c|c|}
\hline \multirow{2}{*}{ Altura (cm) } & \multicolumn{3}{|c|}{ Período de diferimento* } & \multirow{2}{*}{ Média } \\
\hline & Período 1 & Período 2 & Período 3 & \\
\hline \multicolumn{5}{|c|}{ Lâmina foliar viva (kg.ha- $\left.\mathrm{ha}^{-1} \mathrm{MS}\right)$} \\
\hline 10 & 468 & 358 & 787 & 538 \\
\hline 20 & 422 & 302 & 627 & 450 \\
\hline 30 & 431 & 311 & 552 & 431 \\
\hline Média & $440 \mathrm{~b}$ & $323 c$ & $655 \mathrm{a}$ & \\
\hline \multicolumn{5}{|c|}{ Colmo vivo (kg.ha-1 de MS) } \\
\hline 10 & $2.777 \mathrm{aA}$ & $1.304 b B$ & $751 \mathrm{bA}$ & 1.611 \\
\hline 20 & $2.414 \mathrm{aAB}$ & $1.754 \mathrm{bAB}$ & $1.035 \mathrm{cA}$ & 1.734 \\
\hline 30 & $2.083 \mathrm{aB}$ & $2.172 \mathrm{aA}$ & $1.040 \mathrm{bA}$ & 1.765 \\
\hline Média & 2.425 & 1.743 & 942 & \\
\hline \multicolumn{5}{|c|}{ Lâmina foliar morta (kg.ha-1 de MS) } \\
\hline 10 & $1.326 \mathrm{aA}$ & $1.089 \mathrm{aB}$ & $562 \mathrm{bB}$ & 992 \\
\hline 20 & $1.254 \mathrm{aA}$ & $1.375 \mathrm{aAB}$ & $825 \mathrm{bAB}$ & 1.151 \\
\hline 30 & $1.046 \mathrm{bA}$ & $1.551 \mathrm{aA}$ & $968 \mathrm{bA}$ & 1.188 \\
\hline Média & 1.209 & 1.338 & 785 & \\
\hline \multicolumn{5}{|c|}{ Colmo morto (kg.ha-1 de MS) } \\
\hline 10 & 1.699 & 1.580 & 788 & $1.356 \mathrm{~B}$ \\
\hline 20 & 2.254 & 1.883 & 1.498 & $1.879 \mathrm{~A}$ \\
\hline 30 & 1.757 & 2.389 & 1.558 & $1.902 \mathrm{~A}$ \\
\hline Média & $1.903 \mathrm{a}$ & $1.951 \mathrm{a}$ & $1.282 \mathrm{~b}$ & \\
\hline
\end{tabular}

* Períodos de diferimentos 1, 2 e 3 correspondem a 171, 141 e 109 dias. Médias seguidas por diferentes letras minúsculas nas linhas e maiúsculas nas colunas diferiram pelo teste de Student-Newman-Keuls $(\mathrm{P}<0,05)$.

O pasto com menor altura inicial apresentou menor massa de forragem (Tabela 7) e menor altura (Tabela 5), o que pode ter diminuído o sombreamento das folhas e, assim, a senescência foliar. Isso possibilitou um nível de massa de lâmina foliar viva semelhante ( $p>0,05$ ) aos encontrados nas plantas diferidas com maior altura (Tabela 8). Nestas, a massa de forragem (Tabela 7) foi maior no final do período de diferimento, o que indica ocorrência de maior sombreamento das folhas.

Constataram-se também efeitos $(\mathrm{p}<0,05)$ da interação dos fatores, período de diferimento e altura inicial do pasto sobre a massa de lâmina foliar morta (Tabela 8). Em geral, padrão de resposta contrário ao das lâminas foliares vivas foi observado nas lâminas foliares mortas, ou seja, pastos diferidos por maior período tiveram $(\mathrm{p}<0,05)$ maior massa de lâmina foliar morta (Tabela 8). Isso se deve ao acentuado processo de senescência na fase final de crescimento dos pastos mantidos por período longo de rebrotação ${ }^{(12)}$. De modo geral, as menores alturas iniciais dos pastos resultaram $(p<0,05)$ em menor massa de lâmina foliar morta. O rebaixamento dos pastos proporcionou maior penetração de luz solar 
na base do pasto. Com isso, a rebrotação possivelmente ocorreu a partir de novos perfilhos vegetativos, que são mais jovens e possuem menor massa de lâmina foliar morta ${ }^{(4)}$.

A massa de lâmina foliar morta no pasto diferido por longo período (171 dias) não foi modificada pela altura (Tabela 8), devido possivelmente ao longo período em que o pasto ficou diferido, que pode ter anulado o efeito de maior massa residual pós-corte em pasto diferido com maior altura. Já nos pastos manejados com menores períodos de diferimento, o aumento da altura inicial incrementou a massa de lâmina foliar morta (Tabela 8).

Quanto à massa de colmo vivo, houve interação $(\mathrm{p}<0,05)$ entre período de diferimento e altura (Tabela 8). Em geral, os pastos diferidos por período longo (171 dias) tiveram maior massa de colmo vivo em relação aos demais. Entretanto, nos pastos diferidos por 141 dias (Período 2) com altura inicial de 30 $\mathrm{cm}$ ocorreu maior massa de colmo vivo que naqueles diferidos com $10 \mathrm{~cm}$ (Tabela 8).

A massa de colmo morto foi maior $(\mathrm{p}<0,05)$ em pastos manejados com períodos de diferimento mais longos e também aumentou quando os pastos foram diferidos com 20 e $30 \mathrm{~cm}$ em relação àqueles diferidos com $10 \mathrm{~cm}$ (Tabela 8). Em geral, com maior altura no início do diferimento, ocorre maior competição por luz e alongamento de colmo para expor novas folhas na parte superior do pasto, em que a luminosidade é maior. Esse padrão de reposta foi observado na descrição da dinâmica do acúmulo de forragem do capim-mombaça em lotação intermitente ${ }^{(17)}$. Nesse processo, além do alongamento do colmo, que favorece o aumento da massa de colmo vivo, ocorre o sombreamento das folhas mais baixas e dos perfilhos menores, que tendem a morrer, o que contribui para o maior incremento de forragem morta no pasto.

Com base nos dados (Tabelas 3 a 8), o período de diferimento foi o fator que mais afetou as características estruturais do capim-braquiária. Em 2010, todas as características avaliadas foram influenciadas pelo período de diferimento, $50 \%$ pela altura do pasto, e $50 \%$ apresentaram efeito de interação entre os dois fatores. Em 2011, 85\% das características foram influenciadas pelo período de diferimento, $43 \%$ pela altura inicial do pasto, e não houve efeitos de interação entre os fatores.

Ademais, 64,28\% das variáveis respostas foram influenciadas simultaneamente pela altura do pasto e pelo período de diferimento nos dois anos de avaliação. Para essas variáveis respostas, observou-se que os efeitos do período de diferimento e da altura do pasto foram de mesma natureza.

Dessa forma, o período de diferimento foi a ação de manejo que causou mais efeito sobre as características estruturais dos pastos diferidos. Assim, a duração do período de diferimento deve ser uma das principais estratégias de manejo controladas quando se realiza o diferimento de pastagem.

\section{Conclusões}

O período de diferimento longo reduz os efeitos de altura do pasto no início do diferimento sobre as características estruturais da Urochloa decumbens cv. Basilisk. Os pastos de U. decumbens cv. Basilisk diferidos para utilização em julho devem ter períodos de diferimento com duração entre 71 e 109 dias e altura de 20 a $30 \mathrm{~cm}$, no início do período de diferimento. A altura inicial de $10 \mathrm{~cm}$ é recomendada quando se adotar período de diferimento mais longo. 


\section{Referências}

1. Santos MER, Fonseca DM, Euclides VPB, Nascimento Júnior D, Queiróz AC, Ribeiro Júnior JI. Características estruturais e índice de tombamento de Brachiaria decumbens cv. Basilisk em pastagens diferidas. Revista Brasileira de Zootecnia. 2009b;38(4):626-634. Available from: http://www.scielo.br/pdf/rbz/v38n4/06.pdf. Portuguese.

2. Euclides VPM, Filho KE, Arruda ZJ, Figueiredo GR. Desempenho de novilhos em pastagens de Brachiaria decumbens submetidos a diferentes regimes alimentares. Revista Brasileira de Zootecnia. 1998;27(2):246-252.

3. Schio AR, Veloso CM, Silva FF, Ítavo LCV, Mateus RG, Silva RR. Ofertas de forragem para novilhas nelore suplementadas no período de seca e transição seca/águas. Acta Scientiarum Animal Sciences. 2011;33(1):9-17.

4. Santos MER, Fonseca DM, Oliveira IM, Casagrande DR, Balbino EM, Freitas, FP. Correlações entre número de perfilhos, índice de tombamento, massa dos componentes morfológicos e valor nutritivo da forragem em pastos diferidos de capim-braquiária. Revista Brasileira de Zootecnia. 2010a;39(3):487-493. Available from: http://dx.doi.org/10.1590/S1516-35982010000300006. Portuguese.

5. Souza BML, Vilela HH, Santos AL, Santos MER, Júnior DN, Assis CZ, Faria BD, Rocha GO. Piata palisadegrass deferred in the fall: effects of initial height and nitrogen in the sward structure. Revista Brasileira de Zootecnia [On-line version]. 2012;41(5):1134-1139. Available from: http://dx.doi.org/10.1590/S151635982012000500008. English.

6. Sousa BML, Santos MER, Vilela HH, Silveira MCT, Rocha GO, Freitas CAS, Silva NAM, Nascimento Júnior, D. Piata palisade grass deferred with two distinct initial heights: luminous environment and tillering dynamics. Revista Brasileira de Zootecnia. 2013;42,36-43. http://ref.scielo.org/nsxx7g. English.

7. Vilela HH, Sousa BML, Santos MER, Santos AL, Silva NAM, Nascimento Junior, D. Characterization of tillers of piata palisade grass deferred in the fall with varying heights and deferment periods. Acta Scientiarum. Animal Sciences. 2013;35,21-27. http://dx.doi.org/10.4025/actascianimsci.v35i1.13201. English.

8. Trindade JK, Silva SC, Júnior SJS, Giacomini AA, Zeferino CV, Guarda VDM, Carvalho PCF. Composição morfológica da forragem consumida por bovinos de corte durante o rebaixamento do capimmarandu submetido a estratégias de pastejo rotativo. Pesquisa Agropecuária Brasileira [On-line version]. 2007;42(6):p.883-890. Available from: http://dx.doi.org/10.1590/S0100-204X2007000600016. Portuguese.

9. Paula CCL, Euclides VPB, Montagner DB, Lempp B, Difante GS, Carloto, MN. Estrutura do dossel, consumo e desempenho animal em pastos de capim-marandu sob lotação contínua. Arquivo Brasileiro de Medicina Veterinária e Zootecnia. 2012;64(1),169-176. http://ref.scielo.org/kdqtzp. Portuguese.

10.Kopen W. Climatologia. Buenos Aires, Argentina: Gráfica Pan-Americana, 1948.

11.Cantarutti RB, Martins CE, Carvalho MM, Fonseca DM, Arruda ML, Vilela H, Oliveira FTT. Pastagens. In: Ribeiro AC, Guimarães PTG, Alvarez VVH. Comissão de Fertilidade do Solo do Estado de Minas Gerais. Recomendação para o uso de corretivos e fertilizantes em Minas Gerais. Viçosa - 5a Aproximação. 1999;332341.

12.Santos MER, Fonseca DM, Gomes VM, Balbino EM, Magalhães, MA. Estrutura do capim-braquiária durante o diferimento da pastagem. Acta Scientiarum. Animal Sciences. 2010b;32(2),139-145. http://dx.doi.org/10.4025/actascianimsci.v32i2.7922. Portuguese. 
13.Deregibus VA, Sanchez RA, Casal JJ. Effects of light quality on tiller production in Lolium spp. Plant Physiology. 1983;72:900-912.

14.Sbrissia AF, Silva SC. Compensação tamanho/densidade populacional de perfilhos em pastos de capimmarandu. Revista Brasileira de Zootecnia. 2008;37(1):35-47.

15.Morais RV, Fonseca DM, Nascimento Junior D, Ribeiro Júnior JI, Fagundes JL, Moreira LM, Mistura C, Martuscello, J. Demografia de perfilhos basilares em pastagem de Brachiaria decumbens adubada com nitrogênio. Revista Brasileira de Zootecnia; 2006;35(2):380-388. http://ref.scielo.org/c8kcbb. Portuguese.

16.Parsons AJ, Johnson IR, Williams, JHH. Leaf age struture and canopy photosyntesis in rotationally and continuously grazed swards. Grass and Forage Science. 1988;43(1):1-14. http://onlinelibrary.wiley.com/doi/10.1111/j.1365-2494.1988.tb02136.x/abstract.

17.Carnevalli RA, Da Silva SC, Bueno AAO, Hodgson J, Silva GN, Morais JPG. Herbage production and grazing losses in Panicum maximum cv. Mombaça pastures under four grazing managements. Tropical Grasslands. 2006;40(3):165-176. 